\title{
Cervical and oral human papillomavirus infection in women living with human immunodeficiency virus (HIV) and matched HIV-negative controls in Brazil
}

Tamy Taianne Suehiro

Universidade Estadual de Maringa Centro de Ciencias da Saude

Gabrielle Marconi Zago Ferreira Damke

Universidade Estadual de Maringa Centro de Ciencias da Saude

Edilson Damke

Universidade Estadual de Maringa Centro de Ciencias da Saude

Paloma Luana Rodrigues de Azevedo Ramos

Universidade Estadual de Maringa Centro de Ciencias da Saude

Marcela de Andrade Pereira Silva

Universidade Estadual de Maringa Centro de Ciencias da Saude

Sandra Marisa Pelloso

Universidade Estadual de Maringa Centro de Ciencias da Saude

Warner K Huh

University of alabama at birmingham

Ricardo Argemiro Fonseca Franco

University of alabama at birmingham

Vânia Ramos Sela da Silva

Universidade Estadual de Maringa Centro de Ciencias da Saude

Isabel Cristina Scarinci

university of alabama at birmingham

Marcia Edilaine Lopes Consolaro ( $\square$ melconsolaro@gmail.com )

Universidade Estadual de Maringá https://orcid.org/0000-0001-9102-4865

Short Report

Keywords: HPV, HIV, Oral, Cervical

Posted Date: April 6th, 2020

DOI: https://doi.org/10.21203/rs.2.23386/v2 
License: (c) (i) This work is licensed under a Creative Commons Attribution 4.0 International License. Read Full License

Version of Record: A version of this preprint was published at Infectious Agents and Cancer on May 11th, 2020. See the published version at https://doi.org/10.1186/s13027-020-00301-y. 


\section{Abstract}

Background: Despite the demonstrated role of human Papillomavirus (HPV) in the etiology of cervical cancer and the strong evidence suggesting the importance of HPV in the development of oropharyngeal cancer, several aspects concerning the interrelationship between HPV infection in both body sites remain unknown, specifically in human immunodeficiency virus (HIV)-positive (HIV+) female patients. We aimed to assess the prevalence, distribution, and concordance of cervical and oral HPV in HIV+ women and matched HIV-negative (HIV-) controls in Brazil. Material and methods: Cervical and endocervical samples for cytological screening and HPV detection and oral samples were collected from $115 \mathrm{HIV}+$ women using highly active antiretroviral therapy (HAART) and 139 HIV-matched controls (HIV-) in Maringá City, Brazil. Risk factors were assessed using a standardized questionnaire, and the data regarding HIV infection were obtained from the patients' medical records. HPV detection and typing were performed using the Kit Multiplex XGEN Multi HPV Chip HS12. Results: HIV infection was well controlled in this cohort, but women who exhibited detectable HIV load were significantly associated with HPV-positive status in overall $(P=0.03)$ and in cervical mucosa $(P=0.01)$. HIV+ women had significantly more abnormal cytological findings $(P=0.04)$ than HIV- women. Of the $115 \mathrm{HIV}+$ women, $48.7 \%$ were positive for cervical and/or oral HPV DNA; of the 139 HIV- women, $41 \%$ were positive for cervical and/or oral HPV $(P=0.25)$. Both HIV+ and HIV- women had a statistically higher prevalence of cervical HPV infection than oral infection. The concurrent HPV infection in two anatomical sites was similar in HIV+ and HIV- women, however HPV type concordance was not observed. HPV type distribution was different between the anatomical sites in both groups, and HIV+ women presented less common types, mainly in oral mucosa. Conclusion: Our data support the importance of HPV infection in HIV+ women, even when the HIV infection is well controlled. Prospective studies are required to better understand the natural history of HPV infection in both anatomical sites, specifically in HIV+ women.

\section{Background}

The association between persistent high-risk human Papillomavirus (hrHPV), squamous cervical cancer (CC), and some vaginal and anal cancers has been well-established [1-3]. Additionally, recent data demonstrated that HPV is also associated with a subset of head and neck cancers (HNCs) including a worldwide range $₫ 20-80 \%$ of oropharyngeal cancers (OPCs) [4,5]. Individuals living with human immunodeficiency virus (HIV+) are more susceptible to infection, less likely to clear the virus and have higher risk of HPV-related cancers than HIV-negative (HIV-) individuals [6,7]. Although the incidence of overall cancer has decreased in HIV+ individuals with the advent of highly active antiretroviral therapy (HAART), HPV-related CC risk is higher among HIV+ individuals [8,9]. Moreover, in HIV+ women, CC tends to respond poorly to recommended therapies, becomes more aggressive, and may have a worse prognosis [6]. With the increase in survival of HIV+ women due to HAART, progression of oncogenic viral infection into malignancy may result in an increased incidence of HPV-associated oropharyngeal, genital, and anal cancers [8-10]. 
Currently, the HIV/acquired immunodeficiency syndrome (AIDS) pandemic impacts the poorest and the youngest in low-resource settings [11]. HIV+ young women are key populations at high risk for developing HPV-related cancers, particularly in low- and middle-income countries, such as Brazil $[12,13]$. With the recent approval of the 9-valent HPV vaccine, the risk of persistent HPV infection and HPV-related cervical precancerous lesions and malignancies are expected to significantly decrease [14]. With the appropriate vaccination rate thresholds, this vaccine provides a logical rationale for increasing screening intervals considering the anticipated decrease in the burden of disease [15]. Therefore, understanding the specific prevalence, distribution and concordance of cervical and oral HPV in at-risk women in specific geographic locations will provide further insight into the effectiveness of this new vaccine against oral HPV infection that has not been proved yet. Considering the high burden of HPV-related cancers among HIV+ women and the possible effectiveness of a 9-valent HPV vaccine [16], it is critical to understand the prevalence and types of HPV infections in oral and cervical mucosa in HIV+ women (and matched controls). However, while several studies on HIV+ women report cervical, oral, or anal HPV type distribution [17-23], only few studies have addressed concurrent cervical and oral HPV prevalence [24-26]. Despite the demonstrated role of HPV in the etiology of $\mathrm{CC}$ and the strong evidence suggesting the importance of HPV in the development of OPC [27-30], several aspects concerning the interrelationship between oral and cervical infections remain unknown, specifically in HIV+ female patients.

The present study aimed to assess the prevalence, distribution, and concordance of cervical and oral HPV in HIV+ women and matched HIV- controls in the southern region of Brazil, a geographic area with high incidence of HIV and CC.

\section{Methods}

\section{Study population}

Participants included 115 HIV+ women receiving HAART and 139 HIV- aged 19 to 66 years who attended the Specialized Assistance Service (SAE) for sexually transmitted diseases (STD/AIDS in Maringá, southern Brazil), from September 2017 to May 2018. Women with the following characteristics were included in this study: women with confirmed HIV/AIDS diagnosis using two different methods were included in the HIV+ group and women with two HIV/AIDS negative results using two different methods were included in the HIV- group. Exclusion criteria include: women with previous hysterectomy, pregnant, younger than 19 years, and women with no history of sexual intercourse.

Of the $778 \mathrm{HIV}+$ women enrolled in the SAE, 324 were eligible for the study. The sample size was calculated with a HPV prevalence of $50 \%$ in HIV+ women [19], a 95\% confidence interval (Cl), and an error estimate of $5 \%$. With an increase of $10 \%$ for possible participant losses, the total sample size was fixed at 138 randomly selected women. SAE also provides other services and HIV screening. Therefore, to obtain comparable sample, 138 matched controls from the list of patients served by the SAE were identified. The controls were matched on age. Written informed consent was obtained from 254 women and based on their HIV serology status participants were assigned to the HIV+ $(n=115)$ or HIV-group $(n=139)$. 
Participants were interviewed using a standardized questionnaire to obtain demographic information (e.g., age, educational attainment, household income, race/ethnicity), tobacco and alcohol use/abuse, obstetric and gynecologic history (e.g., age at menarche, contraceptive use, number of pregnancies), CC screening, and sexual behaviors (e.g., age at first intercourse, number of sexual partners). Data regarding HIV infection and adherence to HAART were obtained based on the SAE medical records.

\section{Sample collection}

A nursing staff contacted all women, administered the questionnaire, and collected the cervical and oropharyngeal samples. Ecto-/endocervical samples were collected using an Ayre's spatula and cytobrush for cervical cytology and polymerase chain reaction (PCR) for HPV; the samples for HPV testing were stored in ThinPrep ${ }^{\circledR}$ Pap Test solution. The conventional cytological smears were sent to the Clinical Cytology Laboratory at State University of Maringá (UEM) and were graded according to the Bethesda System [31].

Full-mouth oral/oropharyngeal scraping, including the cheeks, tongue, palate, tonsils, and oropharynx, was performed using a sterile brush with soft bristles; samples were stored in ThinPrep ${ }^{\circledR}$ Pap Test solution. Moreover, a gargle sample was obtained by having the participant gargle with $10 \mathrm{~mL}$ of $0.9 \%$ sterile saline for a total of 30 seconds ( $10 \mathrm{~s}$, rinse; $5 \mathrm{~s}$, gargle; 10 s rinse; $5 \mathrm{~s}$, gargle), collected in a sterile cup and stored at $-4^{\circ} \mathrm{C}[20,32]$. All oral/oropharyngeal samples will be referred as "oral samples".

\section{HPV DNA testing}

Detection and typing of HPV were performed using the Kit Multiplex XGEN MULTI HPV CHIP HS12 (Mobius Life Science) following the manufacturer's instructions. The multiplex detected the following 36 HPV types: 18 hrHPV $(16,18,26,31,33,35,39,45,51,52,53,56,58,59,66,68,73$ e 82) and 18 low-risk HPV (IrHPV) $(6,11,40,42,43,44,54,55,61,62,67,69,70,71,72,81,84$ e 89). An additional HPV

universal probe was used to detect other non-specified types of HPV. Samples with invalid outcomes were retested. The second result was considered definitive. Women were considered positive for oropharyngeal HPV if one of the samples, oral and/or scraping, were positive for HPV. Furthermore, women were considered negative for oropharyngeal HPV if their oral and scraping samples were negative for HPV.

\section{Statistical analysis}

Statistical analyses was performed using the GraphPad Prism 6.0 (San Diego, California, USA) software. All variables were expressed as absolute and relative frequencies. For univariate analysis (unadjusted odds ratios [ORs]), categorical variables were compared with HPV infection using the chi-squared and Fisher's exact test. Crude ORs and $95 \%$ confidence intervals (Cls) were calculated. A $P$-value $<0.05$ was considered significant.

\section{Results}


A total of 254 ( $115 \mathrm{HIV}+$ and $139 \mathrm{HIV}-)$ women were included in the study, with all 254 cervical and 508 oral samples (oral scraping and gargle) having sufficient DNA for HPV assessment. All 254 (100\%) participants had conclusive HPV test results from both anatomical sites.

Demographic and clinical characteristics of the two groups of patients are presented in Table 1. The median age was $42.17 \pm 10.18$ years old for HIV+ women and $41.4 \pm 12.31$ years old for HIV- women. $\mathrm{HIV}+$ women compared to HIV- women were significantly more likely to have less than 8 years of schooling $(P=0.0003)$, non-white skin color $(P=0.009)$, first sexual intercourse $<18$ years old $(P=0.04)$, more than two sexual partners ( $P=0.004$ for $2-7$ partners and $P=0.007$ for $>7$ partners), a higher number of parity ( $P=0.0006$ for $1-2$ parities and $P<0.0001$ for $\geq 3$ parities), and less likely to report screening for $\mathrm{CC}$ within the past three years $(P=0.01)$. On the contrary, HIV- women compared to HIV+ women were more likely to be a widowed $(P=0.004)$.

\section{Table 1}

Most HIV+ women presented excellent control of the HIV infection based on the compliance to HAART (80.9\%), preserved CD4+ T lymphocyte count $\left(82.6 \%\right.$ with $>350$ cells $\left./ \mathrm{mm}^{3}\right)$, and suppressed current viral load ( $86.1 \%$ undetectable). Additionally, most of the HIV+ women had documented HIV infection for $<5$ years $(63.5 \%)$ (Table 1$)$.

Cytology showed no signs of malignancy in most women from both groups. Overall, $13.0 \%$ of HIV+ women and $5.0 \%$ of HIV- women presented abnormal cytological findings $(P=0.04)$. Atypical squamous cells of undetermined significance (ASC-US) were observed in $2.6 \%$ of HIV+ women and in $1.4 \%$ of HIVwomen $(P=0.66)$; low-grade squamous intraepithelial lesions (LSIL) were observed in $7.8 \%$ of HIV+ women and in $2.8 \%$ of HIV- women $(P=0.15)$; high-grade squamous intraepithelial lesions (HSIL) were observed in $2.6 \%$ of HIV+ women and $0.8 \%$ of HIV- women $(P=0.33)$.

In overall, 56 (48.7\%) of the $115 \mathrm{HIV}+$ women were positive for cervical and/or oral HPV DNA; 57 (41\%) of the 139 HIV- women were positive for cervical and/or oral HPV $(P=0.25)$. Both HIV+ and HIV- women had a statistically higher prevalence of cervical HPV infection than oral infection, including higher prevalences of hrHPV, IrHPV, universal HPV, and infection by multiple HPV types in cervical samples compared to oral ones, as shown in Table 2.

\section{Table 2}

HPV DNA was detected in oral samples from $17(14.8 \%)$ HIV+ women and $13(9.4 \%)$ HIV- women $(P=$ 0.24) (Table 3). Multiple HPV infections were detected in five samples (4.4\%) of HIV+ women and in four samples (2.9\%) of HIV- women (Table 2). Statistical analysis did not reveal an association between HIV+ status and the presence of HPV DNA in the oral mucosa $(P=0.83)$.

\section{Table 3}


Fifty-one (44.3\%) HIV+ women and 52 (37.4\%) HIV- women had HPV-positive cervical samples $(P=0.48)$ (Table 3). Multiple HPV types were detected in 28 (24.3\%) of HIV+ and in 29 (20.9\%) of HIV-patients (Table 2). There was no significant difference between the HIV+ and HIV-women regarding to HPV types.

To better understand the association between cervical and oral HPV infection, the prevalence of concurrent HPV infection in this population was investigated. Eight (7.0\%) HIV+ women and 7 (5.0\%) HIVwomen had concurrent HPV infection in their cervical and oral samples $(P=0.6)$ (Table 3). In both groups, concordance between HPV types in the cervical and oral samples was not observed.

In the HIV+ group, the most frequent cervical hrHPV types observed were HPV18, HPV45, and HPV58 (14.8\% each). In the oral site, the most prevalent hrHPV was HPV39 (33.3\%) followed by HPV18, HPV45, HPV52, and HPV68 (16.6\% each). The most prevalent cervical IrHPV found in this group was HPV6 (17.5\%) followed by HPV61 (12.5\%), and in oral mucosa, the most prevalent IrHPV was also HPV6 (28.6\%), followed by HPV62 and HPV81 (21.4\%) (Figure 1).

\section{Figure 1}

In the HIV- group, the most prevalent hrHPV in the cervical mucosa was HPV18 (14.2\%), followed by HPV16 and HPV68 (11.9\% each). In the oral site, HPV51 and HPV66 were the most prevalent hrHPV (33.3\% each). The most prevalent IrHPVs in the cervical site were HPV81 (29.0\%) and HPV54 and HPV70 (16.1\% each), and the most prevalent IrHPV in the oral site was HPV6 (30.0\%), followed by HPV43 (20\%) in this group (Figure 2).

\section{Figure 2}

HIV+ women with recent detectable HIV load were significantly associated with HPV-positive status in overall $(P=0.03)$ and HPV-positive status in cervical mucosa $(P=0.01)$ (Table 4).

\section{Table 4}

Analyzing the characteristics of the HIV+ women in relation to HPV status, only current smoking was associated with overall and cervical HPV-positive status ( $P=0.01$ for both), as shown in Table 5 .

\section{Table 5}

\section{Discussion}

In the present study, we aimed to determine the HPV prevalence, distribution, and type concordance between cervical and oral samples of HIV+ women and HIV- matched controls in the southern region of Brazil, a geographic area with high incidence of HIV and CC. Our data demonstrated that HIV+ and HIVwomen had a similar and high HPV prevalence in cervical and in oral sites. However, HIV+ women had higher prevalence of abnormal cytological findings compared to HIV- women. HPV type distribution was different between the anatomical sites within both groups, and HIV+ women commonly presented with 
narrower HPV types distribution, mainly in the oral mucosa. Finally, the frequency of concurrent HPV infection in both sites was low, and HPV type concordance was not observed.

Our results showed that the prevalence of cervical HPV infection was $44.3 \%$ in HIV+ women and $37.4 \%$ in HIV- women. Studies across different populations present varying prevalence of HPV infection, 45-97.1\% in HIV+ women and $44.9-86.5 \%$ in HIV- women in the cervical site $[20,24,25,33]$. The high prevalence of HPV in HIV-negative women in this study can be explained, at least in part, because they were recruited from a Specialized Assistance Service (SAE) for sexually transmitted diseases and therefore are at higher risk for sexually transmitted infections including HPV. Additionally, the prevalence of oral HPV infection in HIV+ women and HIV- control were $14.8 \%$ and $9.4 \%$, respectively. Other studies have shown that the prevalence of HPV infection in the oral site can vary significantly $(12 \%-68.5 \%$ in HIV+ women and $2 \%-$ $31.4 \%$ in HIV- women) [20,24,33].

Although the HIV infection was well controlled and cytology results showed absence of malignancy, abnormal cytological findings were significantly higher in HIV+ women than in HIV- women. These data are consistent with the results of the previous studies showing that HIV+ women are less likely to eliminate the virus with subsequent persistent hrHPV infection and have higher risk of developing precancerous lesion and malignancy, even with the appropriate use of antiretroviral therapy, than HIVwomen $[8,9,19,34,35]$.

Our results demonstrated no significant difference in HPV detection in the uterine cervix or oral mucosa between HIV+ women and HIV- women; however, HPV infection was significantly higher in the cervical mucosa than in the oral site in both groups. These findings are consistent with previous studies suggesting that the natural history of HPV infection varies by anatomical site and a higher prevalence of HPV infection is observed in the cervical mucosa than in the oral mucosa in HIV+ women [36-38]. This can be explained, at least in part, by the evidence that the oral cavity is a hostile environment for the establishment of infectious agents due to the presence of both mechanical and molecular mechanisms related to digestion [39]. More specifically, Fakhry et al. [39] conducted a study that directly compared the local immunologic profiles of the oral cavity and cervix from healthy women using paired secretion specimens. This study showed that the oral cavity contained significantly higher concentrations of immunoregulatory factors that were related to the adaptive and cell-mediated immune response compared to the cervix, which may in part explain the significantly lower burden of sexually transmitted infections such as Chlamydia trachomatis, HPV, and HIV-1 in the oral cavity than in the cervix. According to the authors, these findings provide additional information to better understand the differences in the etiology and natural history of pathogenic agents that are capable of colonizing both the oral cavity and female reproductive tract.

The most prevalent HPV types in cervical samples were hrHPV18 and hrHPV58 in both HIV+ and HIVwomen; however, hrHPV45 and hrHPV16 were frequently detected in HIV+ women and HIV- women, respectively. Prevalence studies around the world have shown that the hrHPV types $16,18,31,33,35,52$, and 58 are the most commonly detected hrHPVs in CC, with hrHPV16 being the most common in all 
populations, with the exception of HIV+ people [1]. Data have consistently shown that HIV+ women are frequently more infected with other hrHPV types than hrHPV16 and hrHPV18, such as hrHPV52 and hrHPV58 [40]. The high prevalence of non-vaccine hrHPV types of 2-valent and 4-valent vaccines in the cervical and oral mucosa found in our study suggests that the 9-valent HPV vaccine is significantly required, which is considered important to reduce the risk of developing HPV-related cancers, specifically in the HIV+ population.

Unlike the distribution of HPV types in cervical samples, HPV type concordance between the HIV+ and HIV- groups in oral samples was not observed. hrHPV39 was the most common hrHPV detected in oral samples of HIV+ women, followed by hrHPV18, hrHPV45, hrHPV52, and hrHPV68, with these types being also frequently found in cervical samples in the same group. However, in HIV- women, the oral hrHPV types observed were totally different, with hrHPV51 and hrHPV66 being the most frequently detected hrHPV. Current evidence has shown that hrHPV16 and hrHPV18 contribute to the majority (approximately $85 \%$ ) of HNC cases worldwide, while the remaining cancers are caused by hrHPV33, hrHPV35, hrHPV52, hrHPV45, hrHPV39, and hrHPV58 [41,42].

Examination of concurrent HPV infections in different anatomical sites has been limited. Hence, we concurrently investigated the prevalence of HPV infection and HPV type distribution in cervical and oral sites to better understand their clinical significance. The simultaneous HPV cervical and oral infection was low in both HIV+ and HIV- women. Moreover, HPV type concordance was not observed, a finding consistent with previous studies [20,24]. Taken together, these observations suggest a different predilection to different anatomical sites of various HPV types, and/or the ability of the two anatomical sites to clear certain HPV types or distinct exposures, while allowing for other HPV types to cause persistent oral and cervical HPV infections.

Prior investigations have demonstrated that engagement in some high risk behaviors may facilitate HPV infection and act as a cofactor to viral persistence, contributing to cancer progression in the oral and cervical mucosa. In the present study, we found that current smoking was associated in HIV+ women with overall and cervical HPV infection. Several studies have already demonstrated that smoking status acts as a predictor and co-factor in cervical HPV infection, which is possibly due to the alteration of the mucosa cells, making them more susceptible to infection, changing the immune mediators, causing DNA damage, and promoting the integration of HPV DNA into the host genome [42-45].

\section{Conclusion And Future Perspectives}

Our study demonstrated that HIV+ and HIV- women in southern Brazil had high HPV prevalence in cervical and oral sites. In this population, HIV+ women had more abnormal cytological findings compared to HIV- women. This study provides important epidemiological data about the potential risk of developing CC. Furthermore, the high prevalence of non-vaccine hrHPV types of the 2-valent and 4-valent vaccines in the cervical and oral mucosa of HIV+ and mainly in HIV- women found in our study highlighting the importance of the 9-valent vaccine. Concurrent HPV infection in both sites was uncommon, and HPV type 
concordance was not observed, likely reflecting the differences in the risk factors and the natural history of HPV infection at the two anatomical sites. These findings support the importance of HPV infection in $\mathrm{HIV}+$ women. Prospective studies are required to better understand the natural history of HPV infection in both anatomical sites, specifically in HIV+ women, and the impact of vaccination programs in at-risk groups.

\section{List Of Abbreviations}

ASC-US: squamous cells of undetermined significance; CC: squamous cervical cancer; Cl: confidence interval; HAART: highly active antiretroviral therapy; HIV: human immunodeficiency virus; HNCs: head and neck cancers; HPV: human Papillomavirus, hrHPV: high-risk HPV; HSILs: high-grade squamous intraepithelial lesions; IrHPV: low-risk HPV; LSILs: low-grade squamous intraepithelial lesions; OPCs: oropharyngeal cancers; OR: odds ratio; Pap: Papanicolaou; SAE: Specialized Assistance Service.

\section{Declarations}

\section{Acknowledgments}

Not applicable.

\section{Authors' contributions}

All the authors contributed to the manuscript. TTS, GMZFD, ED, and MELC searched the literature and prepared the manuscript. SMP collected the biological samples from the women. TTS and MELC wrote the manuscript. MELC, WH, RF, VRSS, SMP, LLRAR, MAPS and ICS participated in the research design and execution. TTS and ED performed the statistical analysis. GMZFD, ED, WH, RAAF, VRSS, SMP, and ICS were involved in revising the manuscript critically for important intellectual content. MELC revised the final version of the manuscript and provided information and suggestions. All the authors read and approved the final draft of the manuscript.

\section{Funding}

This work was supported through a research grant from the NCI (P30CA013148-43S2). The funder had no role in the study design, data collection and analysis, decision to publish, or preparation of the manuscript.

\section{Availability of data and materials}

All data are included in the manuscript.

\section{Ethics approval and consent to participate}


The study involves human participants. This study was approved by the local ethics committee (Committee for Ethics in Research Involving Humans at the State University of Maringá/UEM/Paraná, Brazil [Protocol Number CAAE: 50688815.0.0000.0104/2016], and by Institutional Review Board for Human Use of the University of Alabama at Birmingham [Protocol Number: X150826001]). All procedures performed in studies involving human participants were in accordance with the ethical standards of the institutional and/or national research committee and with the 1964 Declaration of Helsinki and its later amendments or comparable ethical standards. Informed consent was obtained from all individual participants included in the study.

\section{Consent for publication}

Each author gives consent for publication.

\section{Competing interests}

The authors declare that they have no competing interests.

\section{References}

1. Biological agents. Volume 100 B. A review of human carcinogens. IARC Monogr Eval Carcinog risks to humans. France; 2012;100:1-441.

2. Stier EA, Baranoski AS. Human papillomavirus-related diseases in HIV-infected individuals. Curr Opin Oncol.2008;20:541-6.

3. Spangle JM, Munger K. The human papillomavirus type 16 E6 oncoprotein activates mTORC1 signaling and increases protein synthesis. J Virol. 2010;84:9398-407.

4. Marur S, D'Souza G, Westra WH, Forastiere AA. HPV-associated head and neck cancer: a virus-related cancer epidemic. Lancet Oncol. 2010;11:781-9.

5. Beachler DC, Abraham AG, Silverberg MJ, Jing Y, Fakhry C, Gill MJ, et al. Incidence and risk factors of HPV-related and HPV-unrelated Head and Neck Squamous Cell Carcinoma in HIV-infected individuals. Oral Oncol. 2014;50:1169-76.

6. Luque AE, Hitti J, Mwachari C, Lane C, Messing S, Cohn SE, et al. Prevalence of human papillomavirus genotypes in HIV-1-infected women in Seattle, USA and Nairobi, Kenya: results from the Women's HIV Interdisciplinary Network (WHIN). Int J Infect Dis. 2010;14:e810-4.

7. Palefsky J. Human papillomavirus-related disease in people with HIV. Curr Opin HIV AIDS. 2009;4:52-6.

8. Adler DH. The impact of HAART on HPV-related cervical disease. Curr HIV Res. 2010;8:493-7.

9. Liu G, Sharma M, Tan N, Barnabas RV. HIV-positive women have higher risk of human papilloma virus infection, precancerous lesions, and cervical cancer. AIDS. 2018;32:795-08.

10. Ortiz AP, Perez-Irizarry J, Soto-Salgado M, Suarez E, Perez N, Cruz M, et al. Human papillomavirusrelated cancers among people living with AIDS in Puerto Rico. Prev Chronic Dis. 2014;11:E80. 
11. Saffier IP, Kawa H, Harling G. A scoping review of prevalence, incidence and risk factors for HIV infection amongst young people in Brazil. BMC Infect Dis. 2017;17:675.

12. Joura EA, Giuliano AR, Iversen O-E, Bouchard C, Mao C, Mehlsen J, et al. A 9-valent HPV vaccine against infection and intraepithelial neoplasia in women. N Engl J Med. Mass Medical Soc. 2015;372:711-23.

13. Richter KL, van Rensburg EJ, van Heerden WFP, Boy SC. Human papilloma virus types in the oral and cervical mucosa of HIV-positive South African women prior to antiretroviral therapy. J oral Pathol Med Off Publ Int Assoc Oral Pathol Am Acad Oral Pathol. 2008;37:555-9.

14. Videla S, Darwich L, Canadas MP, Paredes R, Tarrats A, Castella E, et al. Epidemiological data of different human papillomavirus genotypes in cervical specimens of HIV-1-infected women without history of cervical pathology. J Acquir Immune Defic Syndr. 2009;50:168-75.

15. Rocha-Brischiliari SC, Gimenes F, de Abreu ALP, Irie MMT, Souza RP, Santana RG, et al. Risk factors for cervical HPV infection and genotypes distribution in HIV-infected South Brazilian women. Infect Agent Cancer. 2014;9:6.

16. Lima MDM, Braz-Silva PH, Pereira SM, Riera C, Coelho AC, Gallottini M. Oral and cervical HPV infection in HIV-positive and HIV-negative women attending a sexual health clinic in Sao Paulo, Brazil. Int J Gynaecol Obstet. 2014;126:33-6.

17. Vacharotayangul P, Rungsiyanont S, Lam-Ubol A, Pankam T, Rodbamrung P, Naorungroj S, et al. Higher prevalence of oral human papillomavirus infection in HIV-positive than HIV-negative Thai men and women. Cancer Epidemiol. 2015;39:917-22.

18. Thorsteinsson K, Storgaard M, Katzenstein TL, Ladelund S, Rønsholt FF, Johansen IS, et al. Prevalence and distribution of cervical high-risk human papillomavirus and cytological abnormalities in women living with HIV in Denmark-the SHADE. BMC Cancer. BioMed Central. 2016;16:866.

19. Konopnicki D, Manigart Y, Gilles C, Barlow P, De Marchin J, Feoli F, et al. High-risk human papillomavirus genotypes distribution in a cohort of HIV-positive women living in Europe: epidemiological implication for vaccination against human papillomavirus. AIDS. 2016;30:425-33.

20. Fakhry C, D'souza G, Sugar E, Weber K, Goshu E, Minkoff H, et al. Relationship between prevalent oral and cervical human papillomavirus infections in human immunodeficiency virus-positive and negative women. J Clin Microbiol. 2006;44:4479-85.

21. Marais DJ, Passmore J-AS, Denny L, Sampson C, Allan BR, Williamson A-L. Cervical and oral human papillomavirus types in HIV-1 positive and negative women with cervical disease in South Africa. J Med Virol. 2008;80:953-9.

22. Menezes LJ, Poongulali S, Tommasino M, Lin H-Y, Kumarasamy N, Fisher KJ, et al. Prevalence and concordance of human papillomavirus infection at multiple anatomic sites among HIV-infected women from Chennai, India. Int J STD AIDS. 2016;27:543-53.

23. Castellsagué X, Alemany L, Quer M, Halec G, Quirós B, Tous S, et al. HPV involvement in head and neck cancers: comprehensive assessment of biomarkers in 3680 patients. $J$ Natl Cancer Inst. 2016;108:djv403. 
24. Taberna M, Mena M, Pavon MA, Alemany L, Gillison ML, Mesia R. Human papillomavirus-related oropharyngeal cancer. Ann Oncol Off J Eur Soc Med Oncol. 2017;28:2386-98.

25. Syrjanen S, Rautava J, Syrjanen K. HPV in Head and Neck Cancer-30 Years of History. Recent results cancer Res Fortschritte der Krebsforsch Prog dans les Rech sur le cancer. 2017;206:3-25.

26. Syrjanen S, Syrjanen K. HPV in Head and Neck Carcinomas: Different HPV Profiles in Oropharyngeal Carcinomas - Why? Acta Cytol. 2019;63:124-42.

27. Solomon D, Nayar R. Bethesda system for cervical-vaginal cytology. Rio Janeiro, RJ Revinter. 2005;67-87.

28. Beachler DC, Sugar EA, Margolick JB, Weber KM, Strickler HD, Wiley DJ, et al. Risk factors for acquisition and clearance of oral human papillomavirus infection among HIV-infected and HIVuninfected adults. Am J Epidemiol. 2015;181:40-53.

29. Thorsteinsson K, Storgaard M, Katzenstein TL, Ladelund S, Rönsholt FF, Johansen IS, et al. Prevalence of cervical, oral, and anal human papillomavirus infection in women living with HIV in Denmark-The SHADE cohort study. J Clin Virol. 2018;105:64-71.

30. Hidalgo-Tenorio C, de Jesus SE, Esquivias J, Pasquau J. High prevalence and incidence of HPVrelated anal cancer precursor lesions in HIV-positive women in the late HAART era. Enfermedades Infecc y Microbiol Clin (English ed). 2018;36:555-62.

31. Hennebery RB, Robinson WR. The occurrence of human papilloma virus (HPV)-related cancers in human immunodeficiency virus (HIV)-infected women compliant with highly active antiretroviral therapy (HAART). J Clin Oncol [Internet]. American Society of Clinical Oncology; 2018;36:185. Available from: https://doi.org/10.1200/JCO.2018.36.7_suppl.185

32. D’Souza G, Fakhry C, Sugar EA, Seaberg EC, Weber K, Minkoff HL, et al. Six-month natural history of oral versus cervical human papillomavirus infection. Int J cancer. 2007;121:143-50.

33. Beachler DC, D’Souza G, Sugar EA, Xiao W, Gillison ML. Natural history of anal vs oral HPV infection in HIV-infected men and women. J Infect Dis. 2013;208:330-9.

34. Isaakidis P, Pimple S, Varghese B, Khan S, Mansoor H, Ladomirska J, et al. HPV infection, cervical abnormalities, and cancer in HIV-infected women in Mumbai, India: 12-month follow-up. Int J Womens Health. 2013;5:487.

35. Fakhry C, Marks MA, Gilman RH, Cabrerra L, Yori P, Kosek M, et al. Comparison of the immune microenvironment of the oral cavity and cervix in healthy women. Cytokine. 2013;64:597-604.

36. McKenzie ND, Kobetz EN, Hnatyszyn J, Twiggs LB, Lucci III JA. Women with HIV are more commonly infected with non-16 and-18 high-risk HPV types. Gynecol Oncol. 2010;116:572-7.

37. Ndiaye C, Mena M, Alemany L, Arbyn M, Castellsagué X, Laporte L, et al. HPV DNA, E6/E7 mRNA, and p16INK4a detection in head and neck cancers: a systematic review and meta-analysis. Lancet Oncol. 2014;15:1319-31.

38. de Martel C, Plummer M, Vignat J, Franceschi S. Worldwide burden of cancer attributable to HPV by site, country and HPV type. Int J cancer. 2017;141:664-70. 
39. Appleby P, Beral V, Berrington de Gonzalez A, Colin D, Franceschi S, Goodill A, et al. Carcinoma of the cervix and tobacco smoking: collaborative reanalysis of individual data on 13,541 women with carcinoma of the cervix and 23,017 women without carcinoma of the cervix from 23 epidemiological studies. Int J cancer. 2006;118:1481-95.

40. Kumar B, Cordell KG, Lee JS, Prince ME, Tran HH, Wolf GT, et al. Response to therapy and outcomes in oropharyngeal cancer are associated with biomarkers including human papillomavirus, epidermal growth factor receptor, gender, and smoking. Int J Radiat Oncol Biol Phys. 2007;69:S109-11.

41. Irimie Al, Braicu C, Cojocneanu R, Magdo L, Onaciu A, Ciocan C, et al. Differential Effect of Smoking on Gene Expression in Head and Neck Cancer Patients. Int J Environ Res Public Health. 2018;15.

\section{Tables}

Table 1 Characteristics of the study population with paired cervical and oral samples, stratified by human immunodeficiency virus (HIV) status 


\begin{tabular}{|c|c|c|c|c|}
\hline & $\begin{array}{c}\text { HIV+ } \\
\mathrm{N}=115 \\
\end{array}$ & $\begin{array}{c}\text { HIV- } \\
\mathrm{N}=139 \\
\end{array}$ & OR (CI) & $P$ \\
\hline & N (\%) & N (\%) & & \\
\hline \multicolumn{5}{|c|}{ :ohort (years) } \\
\hline ean & 42.17 & 41.4 & 0.8 & 0.4 \\
\hline$i-30$ & $16(13.9)$ & $31(22.3)$ & 1 & \\
\hline-40 & $36(31.3)$ & $37(26.6)$ & $1.93(0.88-4.08)$ & 0.09 \\
\hline 40 & $63(54.8)$ & $71(51.1)$ & $1.72(0.84-3.36)$ & 0.12 \\
\hline \multicolumn{5}{|c|}{ l education } \\
\hline \multicolumn{5}{|c|}{ s) } \\
\hline$<8$ & $45(39.1)$ & $26(18.7)$ & $2.79(1.55-5.00)$ & 0.0003 \\
\hline$\geq 8$ & $70(60.9)$ & $113(81.3)$ & 1 & - \\
\hline \multicolumn{5}{|c|}{ al status } \\
\hline arried & $53(46.1)$ & $68(48.9)$ & 1 & \\
\hline narried & $45(39.1)$ & $66(47.5)$ & $1.14(0.67-1.95)$ & 0.69 \\
\hline idowed & $17(14.8)$ & $5(3.6)$ & $0.22(0.08-0.61)$ & 0.004 \\
\hline \multicolumn{5}{|l|}{ color } \\
\hline hite & $48(41.7)$ & $81(58.2)$ & 1 & \\
\hline tt white & $67(58.2)$ & $58(41.7)$ & $1.94(1.17-3.24)$ & 0.009 \\
\hline \multicolumn{5}{|l|}{ rche } \\
\hline \multicolumn{5}{|l|}{ s) } \\
\hline L3 & $56(48.7)$ & $78(56.1)$ & 1 & \\
\hline L3 & $59(51.3)$ & $61(43.9)$ & $1.34(0.80-2.18)$ & 0.25 \\
\hline \multicolumn{5}{|l|}{ If sexual } \\
\hline \multicolumn{5}{|l|}{$t$ (years) } \\
\hline 8 & $79(68.7)$ & $78(56.1)$ & $1.71(1.02-2.89)$ & 0.04 \\
\hline$\geq 18$ & $36(31.3)$ & $61(43.9)$ & 1 & \\
\hline \multicolumn{5}{|c|}{ ll partners (number) } \\
\hline & $6(5.2)$ & $24(17.3)$ & 1 & \\
\hline 7 & 77 (66.9) & $82(59)$ & $3.75(1.43-9.28)$ & 0.004 \\
\hline 7 & $32(27.9)$ & $33(23.7)$ & $3.87(1.36-10.68)$ & 0.007 \\
\hline \multicolumn{5}{|c|}{$r$ (number) } \\
\hline & $3(2.6)$ & $26(18.7)$ & 1 & \\
\hline 2 & $59(51.3)$ & $77(55.4)$ & $6.64(2.14-21.50)$ & 0.0006 \\
\hline 3 & $53(46.1)$ & $36(25.9)$ & $12.76(3.84-41.68)$ & $<0.0001$ \\
\hline \multicolumn{5}{|c|}{$\begin{array}{l}\text { ry of cytology } \\
\text { past three }\end{array}$} \\
\hline is & $42(36.5)$ & $73(52.5)$ & 1 & \\
\hline J & $73(63.5)$ & $66(47.5)$ & $1.92(1.15-3.20)$ & 0.01 \\
\hline \multicolumn{5}{|c|}{$\begin{array}{l}\text { onal } \\
\text { aceptive }\end{array}$} \\
\hline is & $20(17.4)$ & $37(26.6)$ & 1 & \\
\hline J & $95(82.6)$ & $102(73.4)$ & $1.72(0.93-3.19)$ & 0.08 \\
\hline \multicolumn{5}{|l|}{$\begin{array}{l}\text { cologic } \\
\text { tions }\end{array}$} \\
\hline is & $30(26.1)$ & $29(20.8)$ & 1 & \\
\hline כ & 85 (73.9) & $110(79.1)$ & $1.33(0.74-2.40)$ & 0.37 \\
\hline
\end{tabular}




\begin{tabular}{|c|c|c|c|c|}
\hline \multicolumn{5}{|l|}{ 'ette } \\
\hline \multicolumn{5}{|l|}{ ing } \\
\hline is & $30(26.1)$ & $32(23)$ & 1 & \\
\hline J & $56(48.7)$ & $85(61.1)$ & 1.2 & 0.3 \\
\hline i-smoker & $29(25.2)$ & $22(15.8)$ & 0.6 & 0.1 \\
\hline \multicolumn{5}{|l|}{ liagnosis } \\
\hline \multicolumn{5}{|l|}{ s) } \\
\hline j & $73(63.5)$ & - & - & - \\
\hline 0 & $42(36.5)$ & - & - & - \\
\hline LO & $0(0)$ & - & - & - \\
\hline \multicolumn{5}{|l|}{ २T } \\
\hline \multicolumn{5}{|l|}{ liance } \\
\hline is & 93 (80.9) & - & - & - \\
\hline כ & $22(19.1)$ & - & - & - \\
\hline \multirow{2}{*}{\multicolumn{5}{|c|}{$\begin{array}{l}\text { nt CD4 } \\
\left./ \mathrm{mm}^{3}\right)\end{array}$}} \\
\hline & & & & \\
\hline 200 & $3(2.6)$ & - & - & - \\
\hline $10-350$ & $17(14.8)$ & - & - & - \\
\hline 350 & $95(82.6)$ & - & - & - \\
\hline \multicolumn{5}{|l|}{ recent } \\
\hline \multicolumn{5}{|l|}{ load } \\
\hline tectable & $99(86.1)$ & - & - & - \\
\hline ;table & $16(13.9)$ & - & - & - \\
\hline
\end{tabular}

HAART, highly active antiretroviral therapy; OR=Odds ratio; $\mathrm{CI}=$ confidence interval

Table 2 Prevalence of human papillomavirus (HPV) status in the cervical and oral mucosa in human immunodeficiency virus (HIV)-positive and HIV-negative women 


\begin{tabular}{|c|c|c|c|}
\hline & Cervical & Oral & $P$-value comparing cervical and oral HPV prevalence \\
\hline & $\mathbf{N}(\%)$ & $\mathbf{N}(\%)$ & \\
\hline \multicolumn{4}{|c|}{$\mathrm{HIV}+(\mathrm{n}=115)$} \\
\hline \multicolumn{4}{|c|}{ Overall } \\
\hline Positive & $51(44.4)$ & $17(14.8)$ & $<0.0001$ \\
\hline Negative & $64(55.6)$ & $98(85.2)$ & \\
\hline \multicolumn{4}{|c|}{ High-Risk HPV } \\
\hline Positive & $23(20.0)$ & $7(6.1)$ & 0.0028 \\
\hline Negative & $92(80.0)$ & $108(94.0)$ & \\
\hline \multicolumn{4}{|c|}{ Low-Risk HPV } \\
\hline Positive & $37(32.2)$ & $9(7.8)$ & $<0.0001$ \\
\hline Negative & $78(67.8)$ & $106(92.2)$ & \\
\hline \multicolumn{4}{|c|}{ Universal HPV } \\
\hline Positive & $17(14.8)$ & $7(6.1)$ & 0.028 \\
\hline Negative & $98(85.2)$ & $108(93.9)$ & \\
\hline \multicolumn{4}{|c|}{ Multiple types Infections } \\
\hline Positive & $28(24.3)$ & $5(4.4)$ & $<0.0001$ \\
\hline Negative & $87(75.7)$ & $110(95.6)$ & \\
\hline \multicolumn{4}{|c|}{ HIV - $(n=139)$} \\
\hline \multicolumn{4}{|c|}{ Overall } \\
\hline Positive & $52(37.4)$ & $13(9.4)$ & $<0.0001$ \\
\hline Negative & $87(62.6)$ & $126(90.6)$ & \\
\hline \multicolumn{4}{|c|}{ High-Risk HPV } \\
\hline Positive & $33(23.7)$ & $5(3.6)$ & $<0.0001$ \\
\hline Negative & $106(76.3)$ & $134(96.4)$ & \\
\hline \multicolumn{4}{|c|}{ Low-Risk HPV } \\
\hline Positive & $29(20.9)$ & $5(3.6)$ & $<0.0001$ \\
\hline Negative & $110(79.1)$ & $134(96.4)$ & \\
\hline \multicolumn{4}{|c|}{ Universal HPV } \\
\hline Positive & $22(15.8)$ & $4(2.9)$ & 0.0003 \\
\hline Negative & $117(84.2)$ & $135(97.1)$ & \\
\hline \multicolumn{4}{|c|}{ Multiple types infections } \\
\hline Positive & $29(20.9)$ & $4(2.9)$ & \\
\hline Negative & $110(79.1)$ & $135(97.1)$ & $<0.0001$ \\
\hline
\end{tabular}

Table 3 Detection of human papillomavirus (HPV) infection in the oral mucosa and uterine cervix in human immunodeficiency virus (HIV)+ and HIV- women 


\begin{tabular}{|c|c|c|c|}
\hline & $\begin{array}{c}\text { HIV+ } \\
(\mathrm{N}=115) \\
\mathrm{N}(\%) \\
\end{array}$ & $\begin{array}{c}\text { HIV- } \\
(\mathrm{N}=139) \\
\mathrm{N}(\%) \\
\end{array}$ & $P$ \\
\hline Oral mucosa & $17(14.8)$ & $13(9.4)$ & 0.24 \\
\hline Uterine cervix & $51(44.3)$ & $52(37.4)$ & 0.48 \\
\hline Positive samples from oral mucosa of patients with infected uterine cervix & $8(7.0)$ & $7(5.0)$ & 0.6 \\
\hline Positive samples from oral mucosa of patients with uninfected uterine cervix & $3(2.6)$ & $5(3.6)$ & 0.73 \\
\hline
\end{tabular}

Table 4 Characteristics of human immunodeficiency virus (HIV) infection regarding human papillomavirus (HPV) status 


\begin{tabular}{|c|c|c|c|c|c|c|c|c|c|c|c|c|}
\hline \multirow[t]{2}{*}{ es } & $\begin{array}{l}\text { HPV+ } \\
\mathrm{N}=56\end{array}$ & $\begin{array}{l}\text { HPV- } \\
\mathrm{N}=59\end{array}$ & $\begin{array}{l}\text { OR } \\
\text { (CI) }\end{array}$ & $P$ & $\begin{array}{c}\text { Cervical } \\
\text { HPV+ } \\
(\mathrm{N}=51)\end{array}$ & $\begin{array}{c}\text { Cervical } \\
\text { HPV- } \\
(\mathrm{N}=64)\end{array}$ & $\begin{array}{l}\text { OR } \\
\text { (CI) }\end{array}$ & $P$ & $\begin{array}{c}\text { Oral } \\
\text { HPV+ } \\
(\mathrm{N}=11)\end{array}$ & $\begin{array}{c}\text { Oral } \\
\text { HPV- } \\
(\mathrm{N}=104)\end{array}$ & $\begin{array}{l}\text { OR } \\
\text { (CI) }\end{array}$ & $P$ \\
\hline & $\begin{array}{l}\mathrm{N}(\%) \\
\text { (\%) }\end{array}$ & $\mathbf{N}$ & & & N (\%) & N (\%) & & & N (\%) & N (\%) & & \\
\hline \multicolumn{13}{|c|}{$\begin{array}{l}\text { :ed HIV } \\
\text { (years) }\end{array}$} \\
\hline & $\begin{array}{c}39 \\
(69.6)\end{array}$ & $34(57.6)$ & $\begin{array}{l}0.59 \\
(0.27- \\
1.26)\end{array}$ & 0.24 & $\begin{array}{c}36 \\
(70.6)\end{array}$ & $\begin{array}{c}37 \\
(57.8)\end{array}$ & $\begin{array}{c}0.57 \\
(0.26- \\
1.22)\end{array}$ & 0.18 & $\begin{array}{c}7 \\
(63.6)\end{array}$ & $\begin{array}{c}66 \\
(63.5)\end{array}$ & $\begin{array}{c}0.99 \\
(0.31- \\
3.45)\end{array}$ & $>0.99$ \\
\hline & $\begin{array}{c}17 \\
(30.3)\end{array}$ & $25(42.4)$ & 1 & - & $\begin{array}{c}15 \\
(29.4)\end{array}$ & $\begin{array}{c}27 \\
(42.2)\end{array}$ & 1 & & $\begin{array}{c}4 \\
(36.4)\end{array}$ & $\begin{array}{c}38 \\
(36.5)\end{array}$ & 1 & \\
\hline & $0(0)$ & $0(0)$ & - & - & - & - & - & & - & - & - & - \\
\hline \multicolumn{13}{|c|}{ ve to } \\
\hline & $\begin{array}{c}42 \\
(75)\end{array}$ & $51(86.4)$ & $\begin{array}{l}2.12 \\
(0.85- \\
5.54)\end{array}$ & 0.15 & $\begin{array}{c}39 \\
(76.5)\end{array}$ & $\begin{array}{c}54 \\
(84.4)\end{array}$ & $\begin{array}{l}1.66 \\
(0.66- \\
4.45)\end{array}$ & 0.34 & $\begin{array}{c}9 \\
(81.8)\end{array}$ & $\begin{array}{c}84 \\
(80.8)\end{array}$ & $\begin{array}{c}0.93 \\
(0.19- \\
4.18)\end{array}$ & $>0.99$ \\
\hline & $\begin{array}{c}14 \\
(25)\end{array}$ & $8(13.6)$ & 1 & - & $\begin{array}{c}12 \\
(23.5)\end{array}$ & $\begin{array}{c}10 \\
(15.6)\end{array}$ & 1 & & $\begin{array}{c}2 \\
(18.2)\end{array}$ & $\begin{array}{c}20 \\
(19.2)\end{array}$ & 1 & \\
\hline \multicolumn{13}{|c|}{$\begin{array}{l}\text { nt } \\
\left.3 / \mathrm{mm}^{3}\right)\end{array}$} \\
\hline & $\begin{array}{c}3 \\
(5.3)\end{array}$ & $0(0)$ & - & - & $3(5.9)$ & $0(0)$ & - & - & $0(0)$ & $3(2.9)$ & - & - \\
\hline & $\begin{array}{c}9 \\
(16.1)\end{array}$ & $8(13.6)$ & $\begin{array}{l}0.76 \\
(0.26- \\
2.09)\end{array}$ & 0.79 & 8 (15.7) & $9(14.1)$ & $\begin{array}{c}0.81 \\
(0.29- \\
2.39)\end{array}$ & 0.79 & $\begin{array}{c}2 \\
(18.2)\end{array}$ & $\begin{array}{c}15 \\
(14.4)\end{array}$ & $\begin{array}{c}0.78 \\
(0.16- \\
3.9)\end{array}$ & 0.67 \\
\hline & $\begin{array}{c}44 \\
(78.6)\end{array}$ & $51(86.4)$ & 1 & - & $\begin{array}{c}40 \\
(78.4)\end{array}$ & $\begin{array}{c}55 \\
(85.9)\end{array}$ & 1 & & $\begin{array}{c}9 \\
(81.8)\end{array}$ & $\begin{array}{c}86 \\
(82.7)\end{array}$ & 1 & \\
\hline \multicolumn{13}{|c|}{ nt viral } \\
\hline ible & $\begin{array}{c}44 \\
(78.6)\end{array}$ & $55(93.2)$ & 1 & - & $\begin{array}{c}39 \\
(76.5)\end{array}$ & $\begin{array}{c}60 \\
(93.7)\end{array}$ & 1 & & $\begin{array}{c}11 \\
(100)\end{array}$ & $\begin{array}{c}88 \\
(84.6)\end{array}$ & 1 & - \\
\hline $\mathrm{e}$ & $\begin{array}{c}12 \\
(21.4)\end{array}$ & $4(6.8)$ & $\begin{array}{c}3.75 \\
(1.22- \\
11.10) \\
\end{array}$ & 0.03 & $\begin{array}{c}12 \\
(23.5)\end{array}$ & $4(6.3)$ & $\begin{array}{c}4.61 \\
(1.50- \\
13.66) \\
\end{array}$ & 0.01 & $0(0)$ & $\begin{array}{c}16 \\
(15.4)\end{array}$ & - & \\
\hline
\end{tabular}

$\mathrm{OR}=$ Odds ratio; $\mathrm{CI}=$ confidence interval

Table 5 Possible predictors of cervical and oral human papillomavirus (HPV) infection, stratified by HPV status in human immunodeficiency virus (HIV)-positive women 


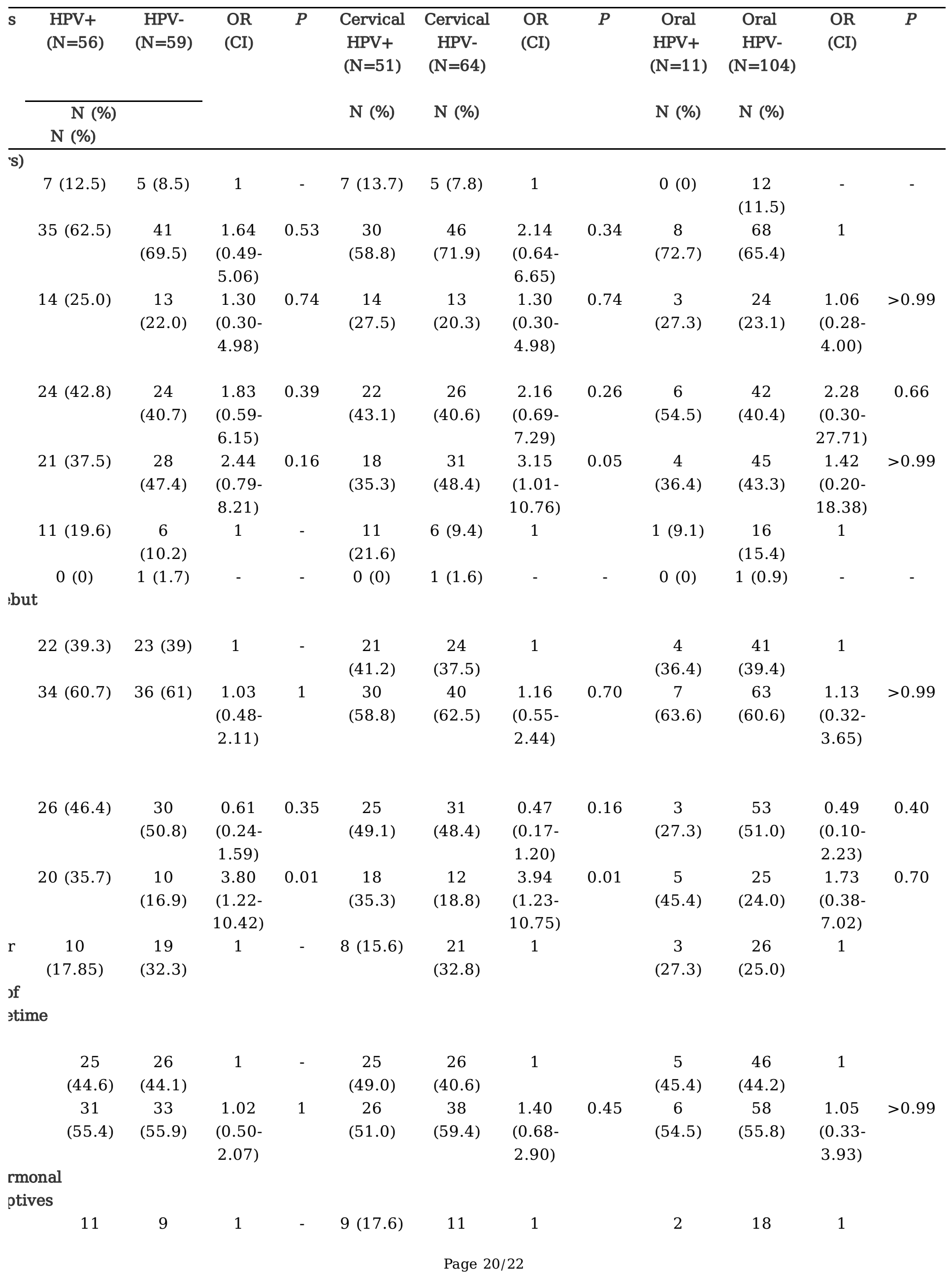


(19.6) (15.2)

$45 \quad 50$

(80.4)

0.9

42

(82.4)

(17.2)

(18.2)

53

$1.03>0.99$

(82.8)

(0.41-

(81.8)

86

$1.06>0.99$

$\mathrm{OR}=$ Odds ratio; $\mathrm{CI}=$ confidence interval

Figures
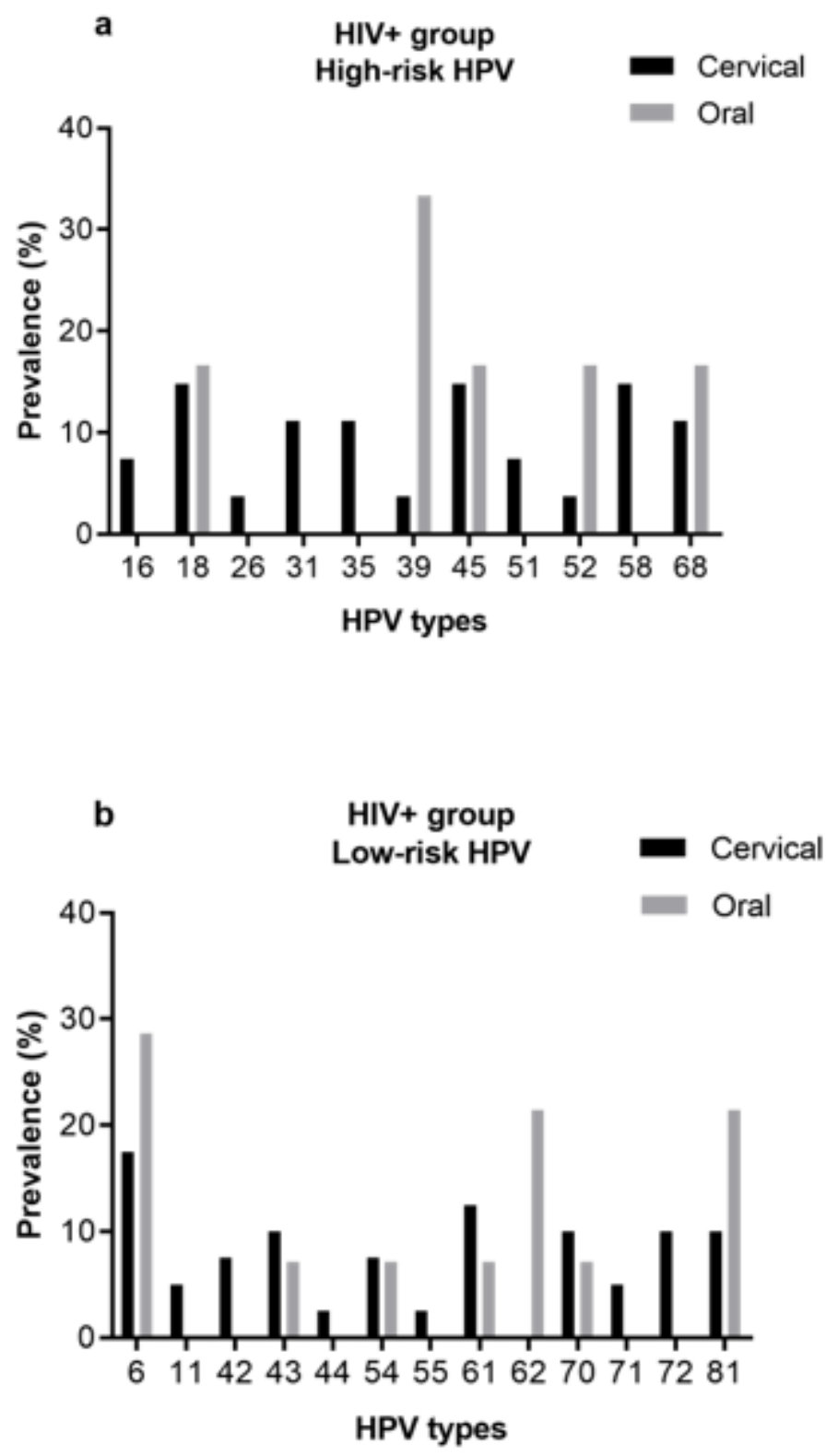

Figure 1

Human Papillomavirus (HPV) type distribution of cervical and oral infections detected among the human immunodeficiency virus-positive group. a High-risk HPV type distribution. b Low-risk HPV type 
distribution.
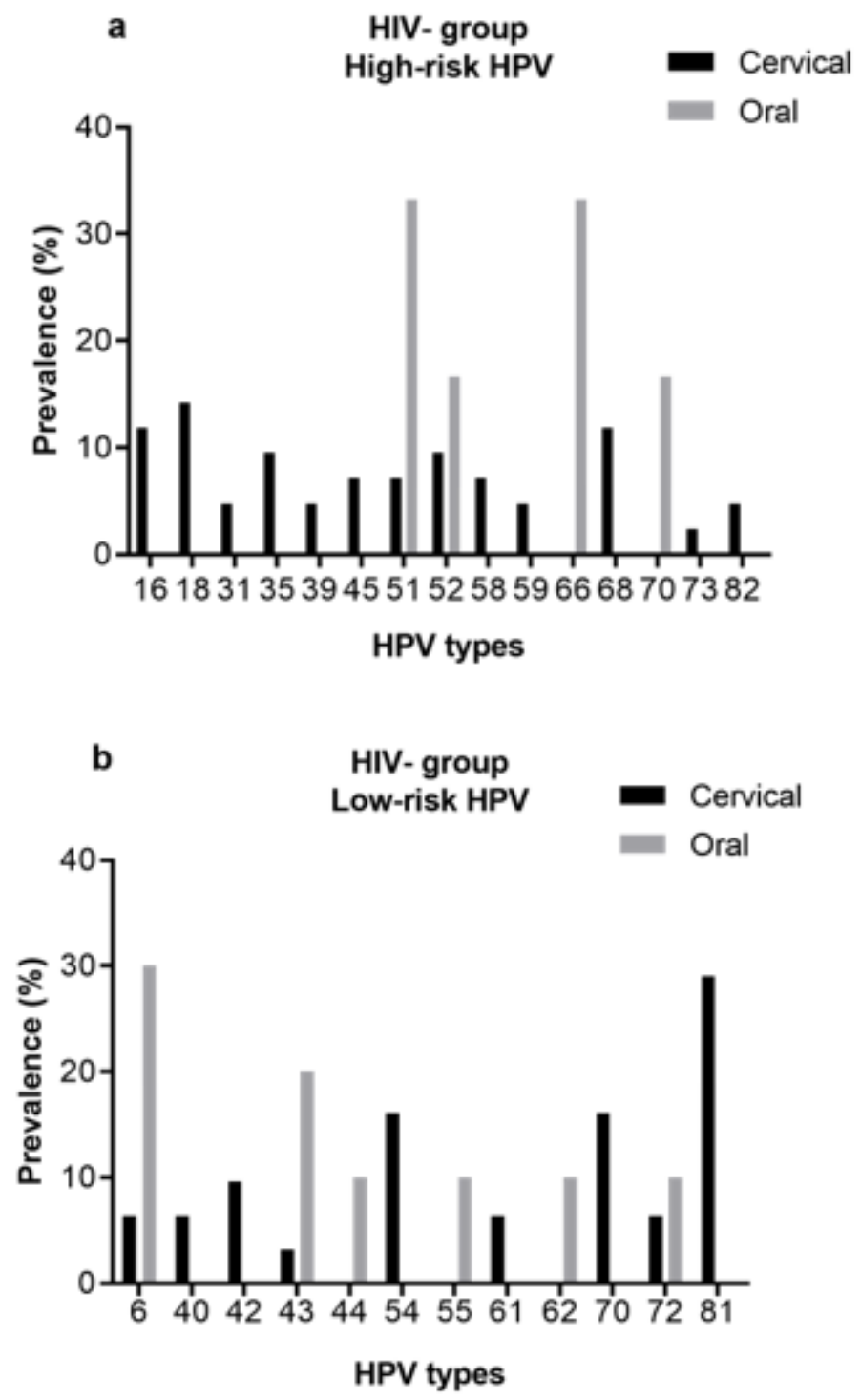

Figure 2

Human Papillomavirus (HPV) type distribution of cervical and oral infections detected among the human immunodeficiency virus-negative group. a High-risk HPV type distribution. b Low-risk HPV type distribution. 